\title{
Obstructive sleep apnoea and type 1 diabetes mellitus
}

\author{
HIANG LENG TAN, ${ }^{1}$ FEAZ BABWAH, ${ }^{2}$ NAJEEB WAHEED, ${ }^{2}$ MUHAMMAD IMRAN BUTT ${ }^{3}$
}

\section{Introduction}

OSA is a common and frequently unrecognised disorder with a prevalence of approximately $4 \%$ in middle-aged men and $2 \%$ in middle-aged women. ${ }^{1}$ It is often found in patients with obesity and type 2 diabetes mellitus. This case report shows the infrequently documented link between OSA and type 1 diabetes and highlights the need to confirm the type of diabetes especially in complex and atypical cases.

\section{Case report}

A 44 year-old teacher was diagnosed with type 2 diabetes in March 2007. He was obese, weighing $135 \mathrm{~kg}$, with a BMI of $34.2 \mathrm{~kg} / \mathrm{m}^{2}$. His initial $\mathrm{HbA}_{1 \mathrm{c}}$ was $9.9 \%$ (85 mmol/mol) and he responded well to lifestyle changes and metformin in a dose of $850 \mathrm{mg}$ three times a day. By March 2008, which was within a year of diagnosis, his $\mathrm{HbA}_{1 \mathrm{c}}$ had improved to 6.6\% (49 $\mathrm{mmol} / \mathrm{mol}$ ). Further cardiovascular assessment confirmed that he also had hypertension and hyperlipidaemia requiring treatment. He was a non-smoker and had no family history of diabetes.

In June 2008, he began feeling unwell with dramatic weight loss of $16 \mathrm{~kg}$ in just 3 months, osmotic symptoms and worsening of his $\mathrm{HbA}_{1 \mathrm{c}}$ to $14.1 \%$ (131 $\left.\mathrm{mmol} / \mathrm{mol}\right)$. Although he was not ketoacidotic, the history pointed to possible type 1 diabetes. He was commenced on a basal bolus insulin regime (glargine + glulisine) which resulted in a quick recovery.

Over the next few years his weight progressively increased as well as his insulin requirement, as shown in Table 1. During one of his clinic consultations he described symptoms suggestive of OSA and was referred for formal sleep studies with the respiratory team. He was asked to stop driving until further notice as per the DVLA guidelines. He scored 12/24 in the Epworth Sleepiness Scale and his overnight pulse oximetry showed 54 × 4\% desaturations per hour consistent with severe OSA. Treatment with CPAP resulted in dramatic improvement in his symptoms and quality of life.

Weston General Hospital, Weston-super-Mare, UK

The County Hospital, Hereford, Wye Valley NHS Trust, UK

Peterborough City Hospital, Peterborough, UK

Address for correspondence: Dr Hiang Leng Tan Department of Diabetes and Endocrinology, Weston General Hospital, Weston-super-Mare, BS23 4TQ, UK.

Tel: +44 (0)1934 636363

E-mail: hiangleng@doctors.org.uk

Br J Diabetes Vasc Dis 2015;15:96-98

http://dx.doi.org/10.15277/bjdvd.2015.020

\author{
Abbreviations and acronyms \\ BMI body mass index \\ CPAP continuous positive airway pressure \\ DKA diabetic ketoacidosis \\ DVLA Driver and Vehicle Licensing Agency \\ GAD glutamic acid decarboxylase \\ GLP-1 glucagon-like peptide-1 \\ $\mathrm{HbA}_{1 \mathrm{c}}$ glycated haemoglobin \\ LADA latent autoimmune diabetes of adulthood \\ NHS National Health Service \\ NICE National Institue for Health and Care Excellence \\ OSA obstructive sleep apnoea
}

Antibodies were also measured to clarify his uncertain diabetes classification, as this would have an impact on his management options. If he indeed had type 2 diabetes, other treatment options could include a GLP-1 analogue or bariatric surgery to assist with weight loss and improving glycaemic contol. Many NHS weight centres offer bariatric surgery for weight loss to people with type 1 diabetes, but there is no NICE guidance for type 1 diabetes and bariatric surgery. In the interim he was again tried on metformin 500 mg once daily and up-titrated to $1 \mathrm{~g}$ twice a day for insulin sparing effect.

Six months after metformin initiation he had lost $7.5 \mathrm{~kg}$ in weight and his insulin requirement was reduced by half with no deterioration in his glycaemic control. LADA, a subtype of type 1 diabetes, was subsequently confirmed by a positive anti-GAD antibody test of $62.7 \mathrm{lU} / \mathrm{mL}$ (normal range $0-10 \mathrm{lU} / \mathrm{ml}$ ). His islet cell antibodies were negative.

\section{Discussion}

The relationship between OSA and type 2 diabetes is well established with a prevalence of $23-50 \%{ }^{2}$ with obesity playing a major link between the two conditions. A few studies have now shown an unexpectedly high prevalence as well in type 1 diabetes patients. Borel et $a^{\beta}$ and Manin et $a^{/ 4}$ showed a prevalence of $40 \%$ and $46 \%$ OSA syndrome respectively in their type 1 diabetes groups. In both studies the type 1 diabetes patients were lean, showing an independent relationship with obesity. Pharyngeal neuropathy, as part of autonomic neuropathy, has been suggested as a possible explanation. ${ }^{3}$

Undiagnosed and untreated OSA can mount a significant health and economic burden to the NHS. There is an independent association between OSA and hypertension which increases cardiac and stroke risk. 5,6 Excessive daytime sleepiness can lead to poor productivity at work, motor vehicular accidents and over- 
Table 1 Trend of $\mathrm{HbA}_{1 c}$, weight and daily insulin requirement

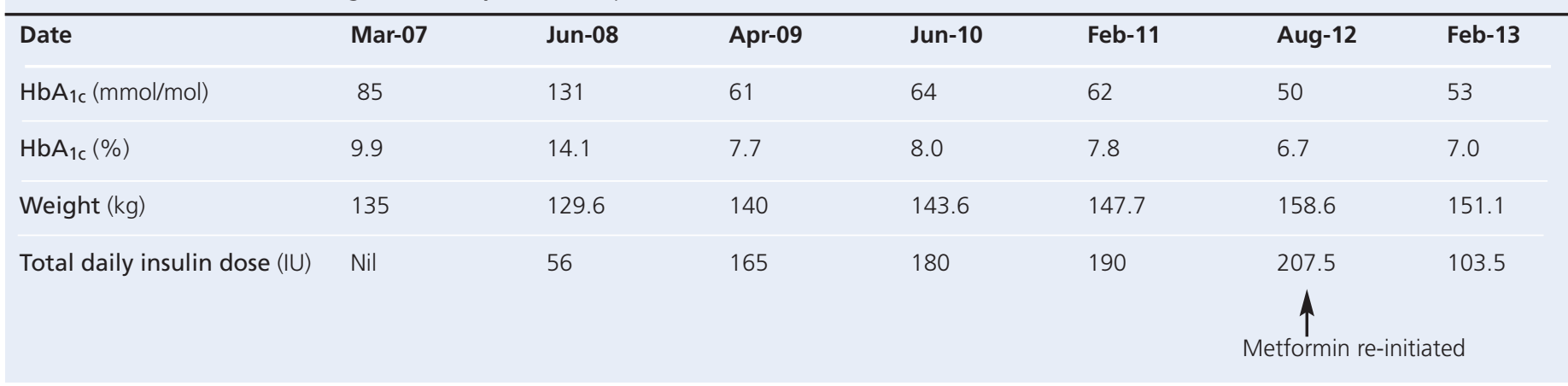

all poor quality of life. There is also the psychosocial impact of impaired spousal relationships.

Our case report highlights the important issue of frequent misclassification of diabetes. Some 50,000 patients in England have been classified with the wrong type of diabetes, as evidenced by research done by the Royal College of General Practitioners and NHS Diabetes. ${ }^{7}$ The biggest problem identified was classifying people with type 2 diabetes when in fact they had type 1 diabetes. Correct identification is important as people with type 1 diabetes have an absolute requirement for insulin to prevent diabetic ketoacidosis, greater glycaemic instability and hypoglycaemia risk. People with type 2 diabetes initially respond well to medication that targets insulin resistance and weight loss although, with time, these patients will develop insulin deficiency as well as requiring insulin.

Differentiating type 1 from type 2 diabetes is a diagnostic challenge. Features of type 1 and type 2 diabetes may be present in the same patient, making this differentiation difficult. Traditionally, patients who are diagnosed at a younger age are assumed to have autoimmune destruction of their pancreatic beta cell and classified as type 1 diabetes, while those in the middle age group are thought to be caused by insulin resistance and thus classed as type 2 diabetes. However, with the increased prevalence of obesity in adolescents, there are now many young patients diagnosed with type 2 diabetes and insulin resistance. At the same time, there are more type 1 diabetes patients diagnosed in the middle age group as well. It is estimated that almost $40 \%$ of type 1 diabetes patients are diagnosed after the age of 30.8 Other features commonly seen in type 1 diabetes patients which may help with diagnosis is the presence of other autoimmune conditions, low BMI and a history of DKA. However, some people may fit the biochemical diagnosis of DKA but in fact do not have insulin deficiency. The clinical presentation and diagnosis of DKA should always be re-examined if there is a query about the type of diabetes.

Anti-islet cell antibodies and anti-GAD antibodies are detected in $70-80 \%$ of patients with type 1 diabetes. ${ }^{9}$ Although there are no clear guidelines on their use and there is no prognostic benefit, these tests are quite useful when the class of diabetes is uncertain and different management options have to be explored, as in our patient. Recently, urinary C-peptide is increasingly being used to differentiate type 1 from type 2

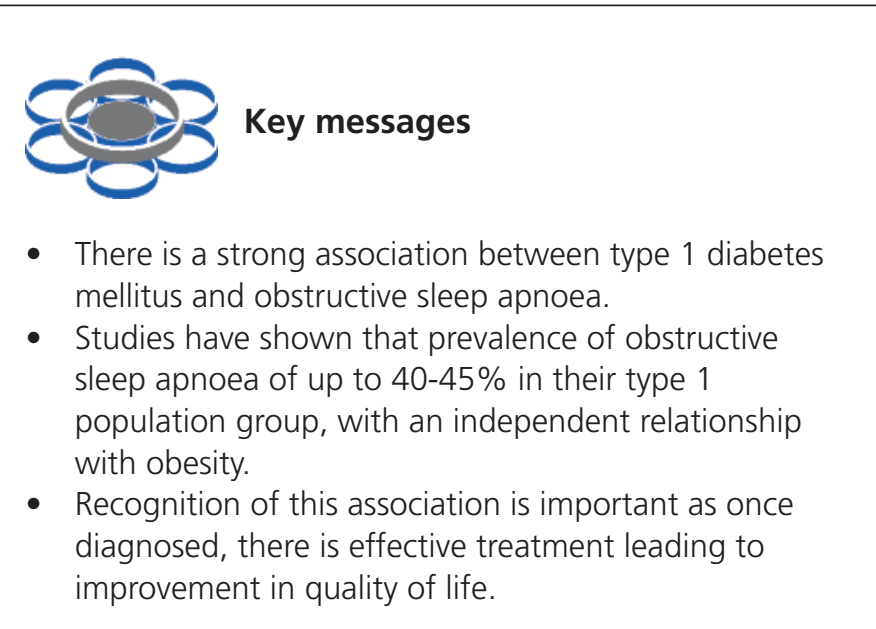

diabetes, although this test is more useful when done 3-5 years after diagnosis when the majority of patients with type 1 diabetes will have low C-peptide. ${ }^{10}$

By definition, our patient has LADA. He had the typical phenotype of type 2 diabetes with positive GAD antibody and slowly progressive beta-cell failure requiring insulin after six months of diagnosis (our patient was commenced on insulin 15 months after diagnosis). Juneja et a/11 found that only islet cell antibodies and GAD antibodies defined LADA, and not BMI, age or clinical presentation. However, making this distinction is largely academic as LADA is actually a subset of type 1 diabetes and the treatment in both of these groups is similar with insulin therapy.

One of the most remarkable patient outcomes in this case is the massive reduction in insulin requirements since the reinitiation of metformin therapy, even though our patient was found to be type 1 diabetic. A randomised double-blind trial by Meyer et a/12 showed that metformin has an insulin-sparing effect in lean type 1 diabetic patients. The same beneficial effect was also found in overweight type 1 diabetic patients. ${ }^{13}$ However, the average reduction in insulin requirement in these studies was about $20 \%$, unlike in our patient where there was $50 \%$ insulin sparing effect.

In summary, there is a strong association between type 1 diabetes and OSA, and this case serves as a reminder of the importance of screening for OSA in this patient group due to its serious implications. Our patient had a vastly improved quality 
of life and was able to resume driving. According to the DVLA, driving must cease until satisfactory control of symptoms has been attained, as did this patient.

\section{Conflict of interest None. Funding sources None.}

\section{References}

1. Young T, Palta M, Dempsey J, Skatrud J, Weber S, Badr S. The occurrence of sleep-disordered breathing among middle-aged adults. N Engl J Med 1993:328(17):1230-5. http://dx.doi.org/10.1056/ NEJM199304293281704

2. Foster GD, Saunder MH, Millman R et al. Obstructive sleep apnea among obese patients with type 2 diabetes. Diabetes Care 2009;32:1017-19. http://dx.doi.org/10.2337/dc08-1776

3. Borel AL, Benhamou PY, Baguet JP et al. High prevalence of obstructive sleep apnoea syndrome in a Type 1 diabetic adult population. Diabet Med 2010:27(11):1328-9 http://dx.doi.org/10.1111/j.1464-5491.2010.03096.x

4. Manin G, Pons A, Baltzinger P et al. Obstructive sleep apnoea in people with Type 1 diabetes: prevalence and association with micro- and macrovascular complications. Diabet Med 2015;32:90-6. http://dx.doi.org/10.1111/dme.12582

5. Marin JM, Carrizo SJ, Vicente E, Agusti AG. Long-term cardiovascular outcomes in men with obstructive sleep apnoea-hypopnoea with or without treatment with continuous positive airway pressure: an obser- vational study. Lancet 2005;365:1046-53. http://dx.doi.org/10.1016/S0140-6736(05)74229-X

6. Yaggi HK, Concato J, Kernan WN, Lichtman JH, Brass LM, Mohsenin V. Obstructive sleep apnea as a risk factor for stroke and death. N Engl $J$ Med 2005;353:2034-41. http://dx.doi.org/10.1056/NEJMoa043104

7. Alert over misdiagnosis of Diabetes. March 2011. (Cited 17 June 2013). Available from URL: http://www. diabetes.co.uk

8. Molbak AG, Christau B, Marner B et al. Incidence of insulin-dependant diabetes mellitus in age groups over 30 years in Denmark. Diabet Med 1994;11(7):650-5. http://dx.doi.org/10.1111/j.1464-5491.1994. tb00327.x

9. Diabetes-related Autoantibodies. (Cited 17 June 2013). Available from URL: http://labtestsonline.org

10. Jones AG, Hattersley AT. The clinical utility of C-peptide measurement in the care of patients with diabetes. Diabet Med 2013;30:803-17. http://dx.doi.org/10.1111/dme.12159

11. Juneja R, Hirsch IB, Naik RG et al. Islet cell antibodies and glutamic acid decarboxylase antibodies, but not the clinical phenotype, help to identify type 1(1/2) diabetes in patients presenting with type 2 diabetes. Metabolism 2001;50:1008-13. http://dx. doi.org/10.1053/meta.2001.25654

12. Meyer L, Guerci B. Metformin and insulin in type 1 diabetes. Diabetes Care 2003:26(5):1655-6. http://dx.doi.org/10.2337/diacare.26.5.1655-a

13. Jacobsen IB, Henriksen JE, Beck-Nielsen $H$. The effect of metformin in overweight patients with type 1 diabetes and poor metabolic control. Basic Clin Pharmacol Toxicol 2009;105:145-9. http://dx.doi.org/10.1111/j.1742-7843.2009.00380.x 